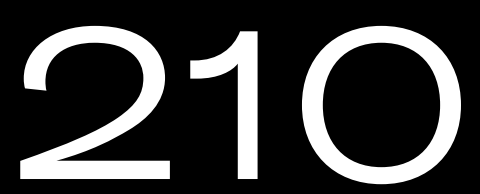

\title{
A espera manca e a biblioteca aberta: Samuel Beckett e Carpeaux
}

Fábio de Souza Andrade

Quando da publicação da primeira edição de sua História da literatura ocidental (1959), redigida em meados dos anos 1940, Carpeaux reviu o texto original da obra para considerar a figura de Samuel Beckett, autor central no século XX, cuja peça mais conhecida, Esperando Godot, acabara de estrear. Anos depois, em 1976, o crítico tornou a se ocupar do dramaturgo irlandês, publicando uma análise de Godot na revista Manchete. Como esse encontro em dois tempos, entre o crítico/historiador e o romancista/dramaturgo, pode revelar aspectos da natureza de seus projetos autorais e dos contextos diversos, mas comunicantes, que os mobilizam?

When the first edition of his História da literatura ocidental (1959-1966) was about to be published, Carpeaux reviewed the original text, written in the mid-1940s, in order to consider the presence of Samuel Beckett, a central author of the twentieth century whose most famous work, Waiting for Godot, premiered in 1953. Years later, in 1976, the critic turned his attention to the Irish playwright one more time, publishing an analysis of Godot in the magazine Manchete. How much this meeting, in two different moments, between the critic/historian and the novelist/playwright can reveal aspects of their authorial projects and the diverse but intertwined contexts that mobilize them?

DOI 10.11606/issn.2447-8997.teresa.2020.156567 
Em "Os mistérios da biblioteca", artigo republicado no segundo e alentado volume de seus Ensaios reunidos, ${ }^{1}$ Otto Maria Carpeaux relata o frisson dos minutos em que, ainda estudante, aguardando uma entrevista com o recém-eleito reitor da Universidade de Viena, pôde passar em revista apressada as estantes de sua biblioteca, investigando, nas escolhas literárias, a intimidade de um espírito europeu universalista, humanista e erudito, que valia o seu respeito.

Relendo os escritos dispersos, originalmente impressos em jornais ( $A$ Manhã, O Jornal e O Estado de S. Paulo, principalmente), entre 1946 e 1971, descobrimo-nos subitamente instalados nos bastidores da formação intelectual de várias gerações de brasileiros pensantes, guiadas pela erudição assombrosa e nada morna do mestre vienense, em seu esforço contínuo de enriquecimento do debate de ideias brasileiro.

Na chegada ao Brasil, em 1939, fugindo do pesadelo nazista (era filho de pai judeu e mãe católica), Carpeaux não foi unanimidade, mas de imediato conquistou papel importante no cenário local. A sólida formação europeia - estudou filosofia, letras e ciências naturais em Viena, onde militou no jornalismo - resultou numa vocação desbravadora, onívora, capaz dos grandes panoramas descritivos que não perdiam a dimensão concreta das singularidades.

Em Croce, dizia, aprendeu as raízes históricas do processo artístico e delas jamais descuidou. Na base do seu pensamento estão também as leituras dos culturalistas alemães e italianos do começo do século, sustentando uma crítica da arte que sempre buscou a construção de pontes entre as diversas esferas da atividade humana (estética, política, econômica). Como Ortega y Gasset, um de seus duplos intelectuais, sabia o quanto indústria cultural e sociedade de massas se opunham a esses esforços compreensivos.

A dimensão enciclopédica de seu conhecimento é de outro tempo e, durante os anos 1960 e 1970, se literalizou - foi responsável, ao lado de

1 CARPEAUX, Otto Maria. Ensaios reunidos: 1946-1971, v. 2. Rio de Janeiro: UniverCidade Editora/Topbooks, 2005 . 
Antonio Houaiss, pelos verbetes de humanidades da Barsa, da DeltaLarousse e da Mirador. Escreveu tanto uma História da literatura ocidental, em oito volumes, quanto uma Uma nova história da música, que transitavam pela diversidade de escolas nacionais, ancoradas numa profunda compreensão dos estilos de época.

A abrangência fáustica desse projeto, abraçado como missão e realizado no perecível papel dos jornais, certamente implicou erros de percurso: uma ou outra avaliação apressada, que se fiava exclusivamente na intuição, algumas generalizações que, tivesse nova chance, certamente Carpeaux matizaria. Mas a recompensa aos leitores vale todos os riscos, levantando as lebres de autores e tradições esquivos e pouco conhecidos entre nós, ainda que com o gesto breve de somente apontá-los, aprofundando e atualizando o debate sobre os mestres e incorporando elementos das correntes interpretativas que surgiram ao longo de sua produção crítica.

O espectro de autores que tratou é amplo o suficiente para, em sua História da literatura ocidental, ocupar um dos oito volumes apenas com índices onomásticos, que tampouco faltam à reunião de seus dispersos. Certamente, seu gosto pelo barroco e pelos clássicos fala alto na excelência dos ensaios a eles dedicados. Mas mesmo nos demais nunca falta interesse. Carpeaux tinha desenvolvida ao extremo a capacidade de apreender a complexidade dos assuntos mais diversos, comunicar o essencial de maneira simples e apresentá-lo a partir de um vivo sentimento da contradição.

No Brasil, suas relações com a militância católica (converteu-se em 1932) e o governo austríaco valeram-lhe, inicialmente, polêmica e reputação política controvertida. Ao cabo de quase meio século de participação pública no Brasil, como crítico, historiador e jornalista, opositor de primeira hora do golpe militar, conquistou o respeito e o reconhecimento de autores ideologicamente tão diversos como Antonio Candido e Olavo de Carvalho. Ainda lemos seus ensaios com o gosto dos que descobrem ângulos novos de mundos desconhecidos.

Talvez o projeto crítico de Carpeaux se assemelhe ao monte impossível de Zenão de Eleia, ${ }^{2}$ no qual um grão mínimo foi sua resposta à obra de Samuel Beckett, ou melhor, a um recorte da obra beckettiana, limitado

2 Em Fim de partida, o paradoxo caro a Beckett aparece tanto no monólogo de abertura de Clov ("Acabou, está acabado, deve estar quase acabando. [Pausa] Os grãos se acumulam, um a um, e um dia, de repente, lá está um monte, um amontoado, o monte impossível."), quanto na narrativa de Hamm ("Depois falar, depressa, como a criança sozinha que se divide em muitas, duas, três, para ter companhia, conversar com os outros, no escuro. [Pausa] Momento sobre momento, pluf, pluf, como os grãos de milho miúdo de... [hesita]... daquele velho Grego, e passa-se a vida esperando que disso resulte uma vida.”). Cf. BECKETT, Samuel. Fim de partida. Tradução de Fábio de Souza Andrade. São Paulo: Cosac Naify, 2010, 2ª ed., pp. 38 e 113. 
no tempo, e em grande parte inserido num contexto da urgência da assimilação local de uma novidade reconhecidamente importante, mas ainda difícil de definir. Ao contrário de Kafka, cuja obra, descoberta precocemente em meio às afinidades centro-europeias, Carpeaux pôde acompanhar em seu arco completo de desenvolvimento, de Beckett experimentou fundamentalmente o impacto primeiro, a explosão de novidade que representou Godot.

Em chave brasileira, a primeira recepção beckettiana contou também, entre seus membros ilustres, Gilda de Mello e Souza, Décio de Almeida Prado e Sábato Magaldi, e mereceria artigo à parte. ${ }^{3}$ Aos interessados na crítica de Carpeaux, no entanto, para além de verificar o quanto ela está ou não em sintonia com um movimento que a ultrapassa - qual seja, a tentativa de apreender, para o melhor, ou domesticar, para o pior, a novidade que Beckett representava em relação às convenções do teatro moderno, no Brasil e no mundo - importa verificar o quanto ela é reveladora de seu projeto crítico, tanto em suas possibilidades, quanto em seus limites.

Mapeando a recepção beckettiana desde os anos 1950, os da encenação de Esperando Godot e Fim de partida, até a contemporaneidade, Peter Boxall enxerga na resposta crítica inicial ao teatro beckettiano duas vertentes antagônicas que deixaram descendência: há "[uma] aproximação crítica a Beckett, que busca compreender como seu radicalismo subverte e desconstrói instituições ideológicas dominantes, correndo em paralelo a uma modalidade de crítica oposta que, em busca de investigar formalmente seus gestos dramáticos o mais rente possível, ao mesmo tempo pressupõe que a sua é uma arte apolítica e benigna".

Da primeira posição, o texto célebre de Theodor Adorno sobre Fim de partida definiria o paradigma, demonstrando o quanto é inútil qualquer tentativa de alcançar a forma negativa, interrogativa e inconcessiva do teatro beckettiano a partir das categorias tradicionais da ideologia humanista, ou da miragem de algum sentido positivo encoberto justamente na ausência de sentido que ela, a forma inassimilável, tomava a si denunciar: "Entendê-la [Fim de partida] só pode querer dizer

3 Cf. souzA, Gilda de Mello e Souza, "Pascal e Beckett”. In: O baile das quatro artes: exercícios de leitura. São Paulo: Duas Cidades, 1980; PRADo, Décio de Almeida. "Teatro de vanguarda”. In: Teatro em progresso. São Paulo: Perspectiva, 2002, e "De Beckett a Shaw”. In: Exercício findo. São Paulo: Perspectiva, 1987; Sábato Magaldi sobre as montagens históricas de Flávio Rangel e Antunes Filho, por exemplo: MAGALDI, Sábato. Amor ao teatro. São Paulo: Edições Sesc, 2014.

4 Tradução livre de BOxall, Peter. Samuel Beckett: Waiting for Godot/Endgame, a reader's guide to essential criticism. Cambridge: Icon Books, 2000, p. 50. 
entender sua ininteligibilidade, reconstruir concretamente o significado do fato de que ela não significa". ${ }^{5}$

Martin Esslin e seu O teatro do absurdo, por sua vez, encarnaram de maneira exemplar a tentativa de acomodar o teatro beckettiano a mais uma expressão, ainda que por recursos mínimos, de verdades essenciais e universais sobre a condição humana, legível, portanto, através das categorias estéticas da tradição dramática e da hermenêutica tradicional de elucidação de significados ocultos; ao conferir peso positivo à sua relutância em significar, substancializando e essencializando sua negatividade, de matriz historicamente determinada, em um conceito abstrato de liberdade e de situação, Esslin aproximava Beckett da filosofia e do romance existencialistas parisienses de seu tempo, naturalizando a estranheza e a radicalidade de sua inovação formal. ${ }^{6}$

Não fosse o estilo de época a ideia que confere vida ao projeto historiográfico literário de Carpeaux, obstinado em escapar às armadilhas de uma moldura estritamente cronológica que, enfeixando tipos ideais da produção de um momento histórico particular, se avizinhasse perigosamente de uma crítica classificatória, feita exclusivamente de análises monográficas e deixando escapar por entre os dedos a teia de tensões que dinamiza tradição e rupturas (entre os estilos, entre as realizações particulares), verdadeira responsável pelo enraizamento da obra na experiência vivida do tempo, a abordagem da obra becketttiana também se dá em meio a esta dialética que recusa tanto o viés estanque, quanto a dissolução das especificidades em modelos abstratos. ${ }^{7}$

No embalo desta primeira onda crítica beckettiana, que coincide com o momento de publicação da História da literatura ocidental (a primeira edição é de 1959, enquanto a redação data de 1944 a 1945), Carpeaux menciona de passagem o irlandês em alguns poucos ensaios avulsos, sempre associando-o a uma seriedade trágica, espécie de refrão-epíteto definidor, e dedicando-lhe uma única avaliação relativamente mais longa, justamente dois parágrafos incluídos na História. ${ }^{8}$ A importância que

\footnotetext{
5 ADORNo, Theodor. "Trying to understand Endgame”. In: Notes to literature.Tradução de Shierry Weber Nicholsen. New York: Columbia University Press, v. 1, p. 243.

6 Esslin, Martin. O teatro do absurdo. Tradução de Bárbara Heliodora. Rio de Janeiro: Zahar, 2018.

7 Ver o preciso e arguto exame do prefácio metodológico da História de Carpeaux que faz Alfredo Bosi, em cotejo com a introdução da Formação da literatura brasileira, de Antonio Candido, em "Por um historicismo renovado: reflexo e reflexão em história literária”. In: Bosı, Alfredo. Literatura e resistência. São Paulo: Companhia das Letras, 2002, pp. 7-53.

8 O índice onomástico do segundo volume de seus ensaios reunidos traz sete menções a Beckett, aproximadamente um quarto das referências a Brecht e um sétimo das alusões a Kafka.
} 
cedo atribuiu à figura de Beckett - que de pronto descreve, na companhia de Rimbaud, como "antiliterária”, dada sua recusa a deixar-se assimilar a modelos esgotados - revela-se pela posição estratégica que o irlandês ocupa no posfácio de balanço da própria empreitada e de seu objeto, a literatura ocidental, no ponto em que a história de Carpeaux a deixa. ${ }^{9} \mathrm{Se}$ Adorno dedica sua Teoria estética a Beckett, o crítico brasileiro encerra sua História sob o mesmo signo, Samuel Beckett sendo o último autor por ele mencionado, na última linha do parágrafo final do último dos oito tomos que a compõem. ${ }^{10}$

Transcrevo a breve, mas reveladora, passagem da História da literatura ocidental em que o mestre austríaco apresenta o então autor do momento no teatro europeu:

Pelo menos relações pessoais com o grupo existencialista teve Samuel Beckett, irlandês que vive na França e escreve com a mesma mestria em inglês e francês; durante certo tempo foi espécie de secretário particular de Joyce; tampouco faltam leituras surrealistas e de Kafka. Mas nada disso diminui sua originalidade singular, de um dos escritores mais solitários deste século. Sua peça dramática En attendant Godot, escrita em francês e depois traduzida para o inglês pelo próprio autor, foi em Paris, em 1952, um grande sucesso, que se tornou depois internacional. Até hoje continua a discussão sobre essa obra dramática, mas misteriosamente estática, para cuja compreensão o próprio Beckett não quis contribuir. É um texto altamente paradoxal, de gravidade assustadora, não realista ou até antirrealista, sem começo nem fim, obra trágica e no entanto iluminada por um atroz humor negro. Parece vazia e acaba em silêncio. É claro que a expressão verbal não importa a esse escritor bilíngue que considera o problema da língua como irresolúvel e, aliás, sem importância. Assim como seus romances enigmáticos, suas peças também são deliberadamente absurdas: em Fin de partie, o diálogo

\footnotetext{
9 O intervalo entre primeira redação e a primeira versão em livro revela a ambição do projeto, de atualização contínua. A importância de Beckett no cenário mundial veio apenas depois da estreia de Godot e a atenção a seus romances anteriores à guerra veio a reboque desta descoberta tardia. Carpeaux, portanto, certamente submeteu o texto a revisões profundas até serem tragados pela boca das impressoras. Assim, o oitavo volume da História retoma, corrige e alarga a incursão prévia do autor às vanguardas históricas do século xx - a seção As revoltas modernistas na literatura - na direção das Tendências contemporâneas, em que Beckett se inclui. 10 "Não se pode prever se se trata, no caso da poesia concreta, de tendência em crescimento ou de mero episódio. Em todo caso, é ela mais um sintoma do esgotamento do conceito tradicional da literatura. O precursor dessa tendência antiliterária foi Rimbaud, que com dezenove anos de idade deixou de escrever versos; e a testemunha principal é hoje Samuel Beckett, cuja última palavra é o silêncio.” In: CARPEAUx, Otto Maria. História da literatura ocidental. Rio de Janeiro, Alhambra, 1984, v. 8, $2^{\mathrm{a}}$ ed., p. 2309.
} 
não tem sentido nenhum, tampouco como os personagens imobilizados. Happy Days é um monólogo sem significação reconhecível. O romance Comment c'est é alegoria de uma condição humana irremediável; e na peça Play repete o segundo ato literalmente o primeiro. É evidente que "há método nessa loucura", e que não se trata de loucura, mas de uma compreensão assustadora da condição humana. Sartre e Beckett são espíritos teóricos: mesmo negando toda e qualquer literatura, eles produzem obras literárias. Mas também há quem viva essas suas próprias obras."

O primeiro ponto a destacar é a aparente consonância de Carpeaux com a leitura de época que associava o Beckett emergente ao existencialismo francês, "clima literário ao qual, naqueles anos, ninguém conseguiu escapar" e, nestes termos, com a direção sinalizada e inaugurada pelo ensaio de Martin Esslin, buscando extrair de sua obra um significado positivo, ainda que de resistência, significado vazado e compreensível em termos de continuidade da tradição do drama burguês, em crise, por certo, mas às voltas como uma "condição humana irremediável" e reconhecível. Significativo que, nestes termos, Beckett seja apresentado menos na vizinhança de Kafka ou Joyce, como um renovador da forma literária, mas antes como um escritor com interessantes implicações filosóficas. ${ }^{12}$ A capacidade de esboçar com meia dúzia de traços um retrato complexo, ainda que mínimo, que apanhe o essencial do problema literário que constitui sua novidade não falha: o bilinguismo, o exílio, o caráter europeu da obra, a importância do impasse e do paradoxo na sua constituição, o gosto pelo comitrágico.

Na contramão da agudeza notável, premido pela concisão necessária a uma empreitada tão gigantesca, aparecem traços fundamentais da obra beckettiana que mereceriam tratamento mais longo para dar conta de sua complexidade e, portanto, certo mal-estar de Carpeaux na impossibilidade de explorar até o fim o que, aqui, só pode intuir e registrar de passagem. Neles se incluem sua dimensão conflitante de

11 CARPEAuX, Otto Maria. História da literatura ocidental. Op. cit, pp. 2284-2285.

12 "A análise do homem e a análise do tempo foram levadas até as últimas possibilidades em Finnegans Wake: por isso é Joyce uma das grandes influências literárias desse tempo. A outra é Kafka. [...] A obra de Kafka é toda ela baseada numa análise ontológica da situação do homem no mundo: mas esta análise está tão completamente escondida nos símbolos e nas parábolas que nenhuma das muitas e divergentes interpretações conseguiria extrair deles a 'filosofia de Kafka'. Faltavam - para complementar a filosofia da linguagem e da história em Joyce - uma ontologia e uma antropologia. Essa foi a contribuição do existencialismo." In: CARPEAUX, Otto Maria. História da literatura ocidental. Op. cit., p. 2280-2281. 
realismo e de antirrealismo, o peso da combinação insólita e singular entre gravidade e humor, o cabo de guerra permanente entre silêncio e palavrório em ruínas que a enforma, a convicção de um fosso entre palavra e mundo que está na origem de seu projeto estético. Ainda que, na brevidade de seus comentários, Carpeaux pareça estar a um passo de formular que o absurdo deliberado da forma beckettiana só ganha compreensibilidade quando pensado em relação à técnica caduca da tradição do drama e romance burguês, e que a sua literatura da despalavra, ao contrário do que chega a afirmar, não despreza, antes valoriza a relevância do problema da língua e da expressão verbal tout court, recusando a expressão verbal clássica e reinventando-a, agora voluntariamente empobrecida, falha e claudicante, este passo não é dado e a conjunção sugerida entre Sartre e Beckett resulta enganadora. ${ }^{13}$ Em Sartre, talvez o espírito teórico empane um pouco o brilho do romancista, mas Beckett é, acima de tudo, um escritor da materialidade da língua e da consideração e denúncia prática da falha estrutural das formas tradicionais de significar que fazem a arte de seu tempo, longe de primordialmente filósofo, portanto.

Fosse esta a última instância de encontro textual entre Beckett e Carpeaux, já seria ela suficientemente fértil em possibilidades, mas a militância do autor de $A$ cinza do purgatório nas mais variadas frentes da imprensa literária tratou de estendê-la. Ao longo dos anos 1970, Carpeaux foi um dos colaboradores mais constantes de uma seção fixa, “As obras-primas que poucos leram”, nas páginas da revista Manchete, a mais popular publicação de variedades da imprensa de então, sucedendo uma rival declinante e mais antiga, O Cruzeiro. Ali, em 1976, Carpeaux reencontrou o teatro beckettiano, dedicando um artigo inteiro exclusivamente a Esperando Godot. ${ }^{14}$

Não apenas o meio de publicação contrasta com a abordagem beckettiana anterior de Carpeaux. O próprio autor examinado ganhara no intervalo outro estatuto: trata-se agora de um Nobel de Literatura, encenado à exaustão tanto em escala global, quanto localmente. Do

13 Assim, o abandono provisório do inglês como primeira língua de expressão, ao contrário do que parece sugerir Carpeaux, não se dá por certeza da irrelevância desta escolha, mas porque não há correspondência ideal possível para a expressão e a experiência. A errância entre línguas é prova da importância cabal para Beckett da questão da língua.

14 Entre os autores frequentes, incluíam-se nomes como Paulo Mendes Campos, Bárbara Heliodora e Carlos Heitor Cony. Heloisa Seixas editou, pela Record, em quatro volumes, uma seleção destes artigos. Cf. CARPEAUX, Otto Maria. "Esperando Godot". In: SEIXAs, Heloísa (org). As obras-primas que poucos leram, v. 3. Rio de Janeiro: Record, 2006, pp. 403-408. 
mesmo ano do artigo, aliás, é a montagem da peça dirigida por Antunes Filho, com um elenco formado exclusivamente por mulheres, encabeçado por Eva Wilma e Lilian Lemmertz. Nestes termos, a perspectiva de Carpeaux se amplia, mesmo atenta à necessidade didática de apresentar autor e obra, e o lugar do Beckett na história literária contemporânea ganha em complexidade e, em que pesem as obsessões críticas que persistem, o retrato como um todo ganha em sugestão e provocação. ${ }^{15}$

Obrigado a enfrentar as dificuldades de apresentar sumariamente uma peça conhecidamente refratária à paráfrase e à síntese, Carpeaux adota a multiplicidade de caminhos: fragiliza, de partida, a associação de Beckett à fórmula difundida por Martin Esslin de um "teatro do absurdo", particularizando a forma beckettiana ("uma espécie de antiteatro ou de não teatro, um gênero inteiramente novo") em relação ao nonsense do teatro de Ionesco, por exemplo. Mostra a primazia estrutural da espera manca do par protagonista, Vladimir e Estragon, sobre qualquer forma de ação dramática clássica na peça. Examina o sentido da simetria imperfeita dos dois atos (continuidade da ausência de movimento progressivo) e o sentido da brutal convivência do segundo par em cena, Pozzo e Lucky.$^{16}$ Expostos os rudimentos da peça, ocupa-se da história das primeiras produções da peça, do sucesso instantâneo que conduziu do respeitado, mas modesto Théâtre de Babylone, em Paris, em 1953, aos palcos mundo afora em pouquíssimo tempo, bem como do percurso artístico pregresso do autor, a pré-história de romancista, o bilinguismo, a atividade na resistência francesa.

O fio condutor de seu interesse por Beckett, contudo, se renova na medida em que encaminha a nova leitura para um exame da obra beckettiana nos termos de uma reinvenção formal da tradição, com consequências crítica e historicamente relevantes, por certo, que extrapola em muito a dimensão de ideias manifestas e evoca um diálogo direto menos com os filósofos que com outros grandes experimentadores e renovadores da expressão literária moderna. No lugar das afinidades decorrentes de um caldo cultural comum com os existencialistas,

\footnotetext{
15 No terreno das posições irredutíveis, está a falta de paciência quase irracional de Carpeaux com os intérpretes e diretores que valorizam o clownesco na obra beckettiana: aos que "substituíram os nomes dos personagens Estragon e Vladimir, em Esperando Godot, por Didi e Gogo: em vez de vagabundos, como no original, aparecem palhaços. Está na hora de acabar com essa palhaçada”. Ibidem, p. 403.

16 A fatura da escrita rápida cobrada pela militância na imprensa chega, aqui, pesada no lapso que leva Carpeaux a trocar sistematicamente os nomes do mestre e do escravo. Seu texto publicado toma, erradamente, Lucky pelo senhor, inclusive atribuindo-lhe a cegueira, no segundo ato, e associa Pozzo ao escravo, que monologa, a contragosto, no primeiro ato e volta, mudo, no segundo (a editora da coletânea em livro manteve a falha original).
} 
interessam-no mais a esta altura as relações de contraste e simetria de Beckett dramaturgo com gigantes como Kafka, Pirandello ou Dostoiévski. Servem-lhe para refutar, com mais ou menos razão, leituras teístas ou marxistas da obra beckettiana abandonando o campo conceitual-filosófico rumo a um exame mais direto dos procedimentos e técnicas literárias.

O cotejo informado de Godot às demais peças beckettianas, a evocação em paralelo de sua obra em prosa, tanto a de juventude, quanto a mais recente, testemunham não somente seu esforço contínuo de aggiornamento, de efeito multiplicado pela circulação vasta que a militância contínua na imprensa propiciava a seus textos, mas também uma disposição crítica determinada a não se render a classificação engessada dos autores e das obras, postura a que o cachimbo do historiador poderia muito bem convidar.

Neste sentido, é significativo que Adorno, justamente o paradigma crítico que estava nas antípodas de sua primeira abordagem detida da obra beckettiana, compareça em destaque neste artigo tardio. Se o juízo manifesto que Carpeaux faz da posição adorniana no artigo, qualificando-a de marxista sem mais, não faz justiça à sua arquitetura intrincada (reduzindo a ideia da precipitação do conteúdo social em forma na obra beckettiana à categoria menor de reflexo, mera expressão de um diagnóstico negativo do capitalismo triunfante), o movimento geral da sua última consideração crítica de Beckett é o de reconhecer, com Adorno, a centralidade da dimensão concreta do embate pessoal, nada economizável, do escritor com a linguagem, na novidade, nada desprezível, por ele representada.

A mencionada impaciência com a relevância que leitores beckettianos concedem ao elemento clownesco em sua obra, expressa, no texto, com extrema contundência digna da sisudez mal humorada que a tradição lhe atribui no trato cotidiano, contrasta com o quanto se ocupa da estranheza do riso acre suscitado por Godot, evidência do crítico agudo que pressente, na tensão, irresolvida, entre o cômico e trágico, uma das muitas chaves combinadas para a compreensão da imensa força expressiva reconhecida em Beckett pelos leitores contemporâneos.

Os que conheceram o artigo originalmente nas páginas da Manchete, possíveis espectadores da montagem brasileira da peça dirigida por Antunes Filho no ano da sua primeira publicação, certamente puderam enxergar o texto e o autor no quadro amplo, moderno e ocidental, a que sua novidade convida. Da mesma forma, por breve que seja, a menção na 
História da literatura ocidental não se restringe a levantar a lebre da sua existência, anotando um nome a reter, mas aponta em notas nervosas como Beckett reage à caducidade do drama realista, criando uma forma feita de paradoxos e expressiva de impasses, difícil de descrever, impossível de ignorar. O rigor e a inquietude de Carpeaux, por outro lado, exemplares, seguem longe de caducar.

FÁBIO DE SOUZA ANDRADE é professor de Teoria Literária e Literatura Comparada da USP, tradutor de Esperando Godot (Companhia das Letras, 2017) e autor de Samuel Beckett: o silêncio possível (Ateliê, 2001). 